\title{
PELATIHAN PEMBUATAN MAKANAN PENUTUP BERUPA LAVA CAKE DAN CHURROS DENGAN TEH HITAM KEPADA IBU-IBU KOREM 052/WIJAYAKRAMA KARAWACI
}

\author{
Sandra Maleachi, Griselda Feliciandria, Gabriella Faustina, Miesyel Samantha \\ Universitas Pelita Harapan \\ Universitas Pelita Harapan \\ Universitas Pelita Harapan \\ Universitas Pelita Harapan
}

sandra.maleachi@uph.edu,griselda.feliciandria@yahoo.com,gabriellaftm@gmail.com,miesyel.samantha@yahoo.com

\begin{abstract}
Abstrak
Industri makanan saat ini telah berkembang pesat, seiring dengan berkembangnya waktu telah banyak pula efek negatif yang timbul dengan penggunaan bahan tambahan kimia pada makanan. Maka dari itu perlu diminimalisir dengan melakukan pembuatan perisa alami sebagai alternatif yaitu dengan menggunakan teh. Teh hitam dipilih karena identik dengan cita rasa Indonesia serta mudah diperoleh dan relatif murah harganya. Menurut banyak studi, teh hitam juga merupakan bahan minuman alami yang menyehatkan karena mengandung senyawa katekin yang merupakan senyawa bioaktif yang dapat menghambat pertumbuhan sel kanker, mengurangi kemungkinan timbulnya penyakit jantung, darah dan pembuluh darah, menyehatkan pencernaan makanan, mulut dan gigi serta beberapa penyakit infeksi lain. Tujuan PkM ini adalah pengajaran dan pelatihan kepada masyarakat, khususnya Ibu-Ibu Korem 052/Wijayakrama bagaimana cara pembuatan makanan penutup gaya barat dengan mudah dan menciptakan rasa baru yang khas Indonesia menggunakan teh hitam. Metode demonstrasi oleh instruktur dan praktik bersama para peserta di laboratorium dapur Program Studi Pengelolaan Perhotelan dipilih berdasarkan lokasi strategis dan peralatan dan perlengkapan memadai. Hasil kegiatan dapat dimanfaatkan para peserta untuk berkreasi lebih lanjut dan juga meningkatkan perekonomian keluarga jika dikomersilkan dalam skala industri rumah tangga.
\end{abstract}

Kata Kunci: makanan penutup, teh hitam, cita rasa, Indonesia

\section{PENDAHULUAN}

World Health Organization pada tahun 2012 menyatakan bahwa pesatnya perkembangan industri makanan saat ini telah banyak menimbulkan efek negatif. Di Indonesia, tingkat kesadaran masyarakat tentang penggunaan bahan makanan tambahan, secara kimia, yang tidak aman bagi kesehatan sangatlah masih relatif tinggi. Hal ini terlihat dengan masih banyaknya penggunaan bahan-bahan kimia berbahaya pada makanan, seperti penggunaan zat pewarna, pemanis, dan pengawet yang penggunaannya dilarang dan atau dibatasi oleh BPOM (Badan Pengawas Obat dan Makanan) Indonesia. Maraknya penggunaan bahan-bahan kimia berbahaya pada makanan membuat dibutuhkannya zat aditif alami untuk meminimalisir bahaya yang ada. 
Teh merupakan salah satu bahan alami yang disediakan alam untuk menjawab salah satu permasalahan di atas. Heiss (2010, p.20) teh sendiri berasal dari tanaman teh, yaitu Camelia Sinensis, yang pertama kali ditemukan di Cina ribuan tahun lalu. Ada dua varian tanaman the yaitu Camelia varian Sinensis dan Assamica. Varian sinensis tumbuh di daerah subtropis seperti Cina, Jepang, Taiwan, Korea dan sebagian India. Sedangkan varian Assamica ditanam di daerah tropis seperti Indonesia, Afrika dan Asia Tenggara. Sekarang ini tanaman the sudah menyebar ke berbagai penjuru dunia sampai Amerika dan Selandia Baru juga benua Eropa. Chrsytal (2014, p.15) menyatakan bahwa hal yang membedakan dari setiap jenis teh adalah proses produksinya.

Secara umum teh dibedakan berdasarkan ada atau tidaknya proses oksidasi saat diproduksi yang kemudian membagi the kedalam empat jenis yaitu teh putih, teh hijau, teh hitam dan teh oolong.

Berikut merupakan rincian singkat pada perbedaan keempat jenis teh yang telah disebutkan di atas:

\section{Teh Putih}

Teh putih merupakan teh yang dibuat dari pucuk daun yang tidak mengalami proses oksidasi dan sewaktu dipetik dilindungi sehingga tidak terkena sinar matahari langsung dengan tujuan menghalangi pembentukan klorofil.

2. Teh Hijau

Teh hijau menggunakan daun teh yang telah mengalami oksidasi dalam jumlah minimal dan biasanya langsung diproses setelah dipetik. Proses oksidasi minimal didapatkan dengan menghentikan proses oksidasi itu sendiri melalui pemanasan dengan cara tradisional Jepang, menggunakan uap, atau cara tradisional Tiongkok, yaitu dengan mengoseng daun teh di atas wajan panas.

3. Teh Hitam
Teh hitam merupakan jenis teh yang banyak ditemui di benua Asia secara keseluruhan. Berbeda dengan teh putih, proses oksidasi pada teh hitam dibiarkan berjalan secara penuh dan dapat menghabiskan waktu sekitar dua sampai empat minggu.

4. Teh Oolong

Teh oolong merupakan teh yang proses oksidasinya dihentikan di tengah-tengah proses antara teh hijau dan teh hitam. Biasanya proses oksidasi dibiarkan sekitar dua sampai tiga hari.

Teh ternyata banyak diminati dan dikonsumsi oleh masyarakat Indonesia. Hal ini terbukti dengan cukup tingginya konsumsi teh per kapita dari Indonesia menempati posisi 22 penikmat the per kapita tertinggi di dunia berdasarkan dari Euro Monitor (2017)

Untuk varian teh yang digemari masyarakat Indonesia, berdasarkan dari data yang diperoleh Top Brand Index, teh hitam merupakan teh yang digemari masyarakat. Top Brand Index menunjukkan bagaimana posisi suatu merek di pasar nasional. Riset yang dilakukan bersifat independen.

Selain itu juga ditemukan minuman yang disebut "teh" namun tidak berasal dari tanaman teh sama sekali, yaitu disebut dengan istilah tisanes. Ratna Somantri (2012, h4)

Seperti sudah diketahui, banyak makanan yang berasal dari luar negeri sudah masuk ke Indonesia, meskipun di Indonesia begitu banyak memiliki sumber daya pangan yang dapat diolah. Dalam era millennial, masyarakat Indonesia cenderung ingin sesuatu yang praktis dan mudah didapatkan, salah satunya contohnya adalah makanan. Dalam program studi ini kami ingin membuat sebuah inovasi yaitu makanan penutup dengan varian rasa teh hitam.

Industri makanan saat ini telah berkembang pesat. Seiring dengan berkembangnya industri makanan telah banyak

Ekonomi, Sosial, dan Budaya

1553 
pula efek negatif yang timbul. Ratnani (2009, h1). Di Indonesia tingkat kesadaran masyarakat tentang penggunaan bahan tambahan kimia untuk makanan relatif masih rendah. Hal ini terlihat dengan semakin banyaknya penggunaan bahan tambahan kimia yang berbahaya bagi kesehatan yang terus semakin meluas penggunaannya, misalnya penggunaan zat pewarna, pemanis, pengawet, dan sebagainya.

Pembuatan perisa buatan (sintesis) perlu diminimalisir dengan melakukan pembuatan perisa alami sebagai alternatif. Moentamaria, Againa, Ridhawati, Chumaidi, \& Hendrawati (2016, h85).

Teh merupakan bahan minuman alami yang menyehatkan karena di dalamnya terkandung senyawa katekin yang merupakan senyawa bioaktif yang dapat menghambat pertumbuhan sel kanker, mengurangi kemungkinan timbulnya penyakit jantung, darah dan pembuluh darah, menyehatkan pencernaan makanan, mulut dan gigi serta beberapa penyakit infeksi lain. Yulianto, Arifan, Ariwibowo, Hartati, \& Mustikaningtyas (2007, h24).

Teh ternyata banyak diminati dan dikonsumsi oleh masyarakat Indonesia. Varian teh yang bermacam-macam mendorong masyarakat untuk mencoba dan kembali untuk menikmati teh. Di Indonesia teh dipasarkan dalam tiga bentuk yaitu bubuk, celup dan Ready to Drink (RTD) yang siap minum. Menurut penelitian dalam Jurnal Faktor Determinan Referensi dan Perilaku Konsumsi Teh Hitam dan Hijau, sebagian besar responden lebih memilih teh hitam dalam bentuk celup. Berdasarkan hasil penelitian tersebut bahwa masyarakat Indonesia relatif memilih teh hitam dibandingkan dengan teh jenis lainnya. Berdasarkan hal tersebut, diangkatlah teh hitam sebagai bahan alternatif dari perisa alami.

Dari sisi gaya hidup, salah satu yang populer dan melibatkan teh adalah acara afternoon tea atau tradisi minum teh di sore hari, Moffat (2013, h15) menjabarkan bahwa afternoon tea pertama kali diperkenalkan di Inggris oleh Anna, Duchess of Bedford ketujuh, pada tahun 1840. Afternoon tea merupakan kegiatan untuk menikmati teh, karena saat itu minum teh dianggap sebagai aktivitas di kalangan bangsawan. Minum teh selalu didampingi dengan kudapan asin dan makanan penutup berukuran sekali atau dua kali gigit. Kebiasaan ini dilakukan pada sekitar jam tiga sore sampai 4 sore untuk mengisi waktu luang dari jeda panjang antara makan siang dan makan malam. Menurut Heiss (2010, h25) budaya setiap bangsa memiliki nilai sentimental tersendiri, demikian halnya dengan tradisi afternoon tea di Inggris. Pada saat aktivitas afternoon tea berlangsung, hal tersebut selalu digambarkan sebagai waktu minum teh yang menyenangkan bersama keluarga, sanak saudara atau handai taulan yang diundang untuk minum teh di sore hari dilengkapi dengan aneka kudapan dan makanan penutup.

Makanan penutup identik dengan makanan manis bukanlah hal asing untuk orang Indonesia. Menurut Badan Penelitian dan Pengembangan Kesehatan Kementrian Kesehatan RI tahun 2013, sebanyak 53,1\% penduduk Indonesia di atas umur 10 tahun mengkonsumsi makanan manis setiap hari dan selalu bertumbuh sampai saat ini. Masyarakat Indonesia pun sudah memiliki tradisi dalam mengkonsumsi makanan penutup. Hal ini diperkuat dengan banyaknya variasi makanan penutup manis dan tradisional yang tersedia di pasaran dengan harga terjangkau oleh hampir seluruh lapisan masyarakat. Beberapa contohnya adalah klepon, kue lapis, nagasari, es campur dan es cendol, dan masih banyak lagi.

Menurut Krondl (2011, p8) dessert atau makanan penutup merupakan hidangan bercita rasa manis disajikan setelah hidangan utama. Dia juga menyebutkan bahwa makanan penutup merupakan fenomena budaya yang tidak tergantikan dengan evolusi dunia sehingga akan bertahan dalam waktu lama. Makanan penutup juga juga sering disebut dengan hidangan Ekonomi, Sosial, dan Budaya

1554 
pencuci mulut karena rasanya manis dan menyegarkan. Makanan penutup dibedakan menjadi tiga tipe, pertama adalah hot dessert disajikan dalam suhu 40-50 derajat Celcius, kedua cold dessert, disajikan dalam suhu dingin atau suhu ruangan, ketiga adalah frozen dessert disajikan dalam keadaan beku. Berdasarkan dari banyaknya referensi mengenai hidangan penutup, maka masyarakat Indonesia diharapkan dapat membuat kreasi makanan penutup yang unik dan kreatif menggunakan bahan-bahan alami dari Indonesia, seperti teh hitam sebagai perisa alami. Besar harapan pada masa mendatang untuk terus dilakukan pengembangan dan eksplorasi ilmu pengetahuan dan keterampilan terhadap berbagai ragam hidangan penutup berperisa alami khas Indonesia.

\section{METODE}

Langkah-langkah sistematis yang dilakukan dalam kegiatan pengabdian masyarakat.

\section{Tahap Awal}

Diawali dengan riset data sekunder berupa referensi resep-resep makanan penutup melalui buku dan internet. Setelah mendapatkan referensi yang sesuai, kemudian dilakukanlah pengumpulan data primer melalui wawancara dengan para ahli, penelitian, penyebaran kuesioner, dan melakukan eksperimen. Pengumpulan data menggunakan kuesioner dengan melakukan pengujian organoleptik dan membagikan kuesioner uji mutu hedonik kepada 4 panelis terbatas yang telah ditentukan. Lava cake dan churros dipilih sebagai materi pelatihan, dengan pertimbangan tingkat kemudahan, tingkat keberhasilan, rasa dan trend masa kini.
Adapun daftar panelis terbatas serta keahliannya dapat dilihat pada tabel berikut ini:

Tabel 1. Daftar Panelis Terbatas

\begin{tabular}{ccc}
\hline No. & Nama & Status \\
\hline 1 & $\begin{array}{c}\text { Aan } \\
\text { Nurhasanah } \\
\text { Christina } \\
\text { Handojo } \\
\text { Djauhar }\end{array}$ & Dosen \\
2 & Arifin & Pengampu \\
3 & Lice Sari & $\begin{array}{c}\text { Roti dan } \\
\text { Kue }\end{array}$ \\
4 & & \\
\hline
\end{tabular}

Setelah melalui empat kali eksperimen, maka dipilihlah 2 produk makanan penutup yaitu: lava cake dan churros untuk program PkM

\section{Pemilihan peserta PKM}

Berdasarkan faktor permintaan dan lokasi yang berdekatan maka dipilihlah 25 peserta yang merupakan ibu-ibu dari Korem 052/Wijayakrama, J1. Boulevard Diponegoro, Lippo Karawaci, Tangerang.

\section{Tempat pelaksanaan PKM}

Hari dan Tanggal: Sabtu, 24 November 2018

Tempat: Dapur Praktik Pastry Fakultas Pariwisata UPH

\section{Pelaksanaan PKM}

Acara yang diselenggarakan pada Sabtu 24 November 2018 mengenai Pengabdian kepada Masyarakat kepada ibu-ibu Korem 052/Wijayakrama berlangsung selama 3 jam. Dimulai dengan pembukaan acara, membagikan goodie bag dan juga penjelasan mengenai teh 
hitam yang akan digunakan sebagai perisa dalam lava cake dan churros yang akan dibuat.

Berikut merupakan bagian yang terdapat dalam penjelasan mengenai teh hitam sebagai perisa alami:

a. Teh

Penjelasan tentang berbagai macam teh berdasarkan proses oksidasinya

b. Mengapa Teh Hitam?

Penjelasan definisi teh hitam serta berbagai jenis teh hitam yang ada di Indonesia serta mengapa menggunakan teh hitam sebagai perisa alami.

c. Afternoon tea

Menjelaskan definisi dari afternoon tea and sejarahnya serta hubungannya antara teh dan makanan penutup.

d. Klasifikasi Makanan Penutup Menjelaskan pembagian makanan penutup menurut suhu penyajiannya sehingga sampai di kategori lava cake dan churros yang termasuk hot dessert.

e. Peralatan dan Perlengkapan

Penjelaskan mengenai peralatan dan perlengkapan yang akan digunakan untuk membuat lava cake dan churros.

Kemudian dilanjutkan dengan pembagian kelompok dan pembuatan produk lava cake dan churros berperisa teh hitam di dalam dapur Lab. Pastry Fakultas Pariwisata UPH. Diakhiri dengan pemberian sertifikat dan foto bersama.

Kegiatan ini dilaksanakan di Lab. Pastry Fakultas Pariwisata UPH. Adapun bentuk kegiatan yang dilakukan adalah praktikum mengenai cara membuat lava cake dan churros kepada ibu-ibu Korem 052/Wijayakrama sebanyak kurang lebih 25 orang. Peserta akan dibagi menjadi 5 kelompok dan setiap kelompok akan mencoba membuat sesuai dengan yang diajarkan oleh tim pelaksana. Kemudian hasil makanan yang dibuat akan diletakan di meja display yang nantinya semua peserta dapat mencoba masakan hasil kreasi mereka di akhir acara.

Acara ini berjalan dengan cukup baik dan mendapatkan masukan dan umpan balik yang baik dari para anggota mengenai acara pada hari tersebut, seperti tertera di lembar evaluasi PkM. Antusiasme para peserta terlihat saat pelaksanaan kegiatan membuat produk dan saat melihat hasil yang dibuat.

\section{HASIL DAN PEMBAHASAN}

Proses pembuatan lava cake dan churros berjalan dengan lancar dikarenakan persiapan yang matang dan proses pembuatan makanan penutup yang sederhana dan mudah dimengerti dan dilaksanakan oleh ibu - ibu Korem 052/Wijayakrama.

Pengaplikasian teh hitam untuk lava cake dan churros sangatlah murah dan mudah sehingga ibu-ibu pun terinspirasi untuk membuat varian makanan penutup lain dengan menggunakan perisa teh hitam.

Hasil dari kegiatan ini adalah memperluas dan memperdalam pengetahuan ibu-ibu peserta untuk dapat mempraktikkannya juga di rumah, serta dapat bernilai ekonomis jika menjadi industri berskala rumah tangga.

\section{KESIMPULAN DAN SARAN}

Berdasarkan acara Pengabdian kepada Masyarakat yang berjudul Pembuatan Lava Cake dan Churros dengan Varian Rasa Teh Hitam yang dilaksanakan pada 24 November 2018, dapat disimpulkan bahwa acara PkM tersebut berjalan cukup lancar dan mencapai tujuan yang ingin dicapai. Peserta datang dengat tepat waktu yang sudah ditentukan pukul delapan pagi. Peserta merasa acara tersebut

$$
\text { Ekonomi, Sosial, dan Budaya }
$$


sangat bermanfaat dikarenakan pengetahuan baru yang mereka dapat diaplikasikan di kehidupan mereka sehari-hari. Selain itu, peserta juga dapat membawa pulang hasil karya mereka untuk membagikannya kepada keluargakeluarga. Panitia penyelenggara serta fasilitator juga sudah menjalankan tugas - tugas sesuai bagiannya. Namun masih ditemukan beberapa kendala teknis saat acara berlangsung baik disebabkan oleh pihak penyelenggara, peserta, dan fasilitator. Kendala tersebut antara lain adalah oven yang dipakar dalam keadaan kurang baik, sehingga menyebabkan beberapa lava cake dan churros buatan para peserta menjadi kurang sempurna dalam dimensi kematangan, kurangnya pemberitahuan dari pihak peserta kepada pihak penyelenggara mengenai nama nama peserta sehingga terjadi kesalahan pencetakkan sertifikat peserta dan daftar hadir, serta kekurangan lainnya yang disebabkan oleh pihak penyelenggara salah satunya adalah kurangnya persiapan acara pembuka sehingga menyebabkan perubahan urutan acara secara mendadak. Meskipun masih didapati beberapa kekurangan, acara PkM ini tetap dapat mencapai tujuan awal dari PkM itu sendiri yaitu memberikan pengabdian kepada masyarakat dalam bentuk pelatihan pembuatan makanan penutup dengan menggunakan perisa alami yaitu teh hitam.

Kendala tersebut antara lain adalah mic yang kurang baik kondisinya sehingga suara $M C$ kurang terdengar di dalam dapur, mesin pemanggang dalam keadaan kurang baik menyebabkan makanan - makanan buatan para peserta beberapa gagal, kurangnya pemberitahuan dari pihak peserta kepada pihak penyelenggara mengenai nama - nama peserta sehingga terjadi kesalahan pencetakkan sertifikat peserta dan daftar hadir, serta kekurangan lainnya yang disebabkan oleh pihak penyelenggara salah satunya adalah kurangnya persiapan acara pembuka sehingga menyebabkan perubahan rundown secara mendadak. Meskipun masih didapati beberapa kekurangan, acara PkM ini tetap dapat mencapai tujuan awal dari PkM itu sendiri yaitu memberikan pengabdian kepada masyarakat dalam bentuk pembelajaran memasak makanan penutup dengan menggunakan perisa alami yaitu teh hitam.

Adapun saran kepada Universitas Pelita Harapan adalah sebagai berikut:

1. Menyediakan fasilitas yang lebih baik seperti kompor yang sepenuhnya menyala dan mesin pemanggang yang baik demi kelangsungan acara dan tidak membahayakan pihak manapun.

2. Menyediakan soundsystem yang lebih baik lagi seperti portable mic yang didukung dengan speaker yang bagus.

Saran kepada penyelenggara acara

3. Mempersiapkan segala sesuatu lebih matang seperti waktu untuk persiapan agar acara dapat berjalan sesuai dengan rundown yang telah ditentukan.

4. Mempersiapkan rundown acara lebih baik seperti saat pembagian teh kepada ibu - ibu peserta yang seharusnya bukan dilaksanakan di awal acara melainkan di tengah acara.

5. Mempersiapkan lebih baik lagi anggota pelaksana kegiatan sehingga semuanya berjalan sesuai pekerjaan yang sudah ditentukan masing-masing.

Saran kepada peserta

6. Mempersiapkan nama peserta dengan baik agar tidak terjadi kesalahan cetak baik pada daftar hadir, sertifikat dan hal lainnya.

7. Memberi pemberitahuan yang tidak mendadak kepada pihak penyelenggara agar acara dapat dilaksanakan semaksimal mungkin.

Ekonomi, Sosial, dan Budaya 

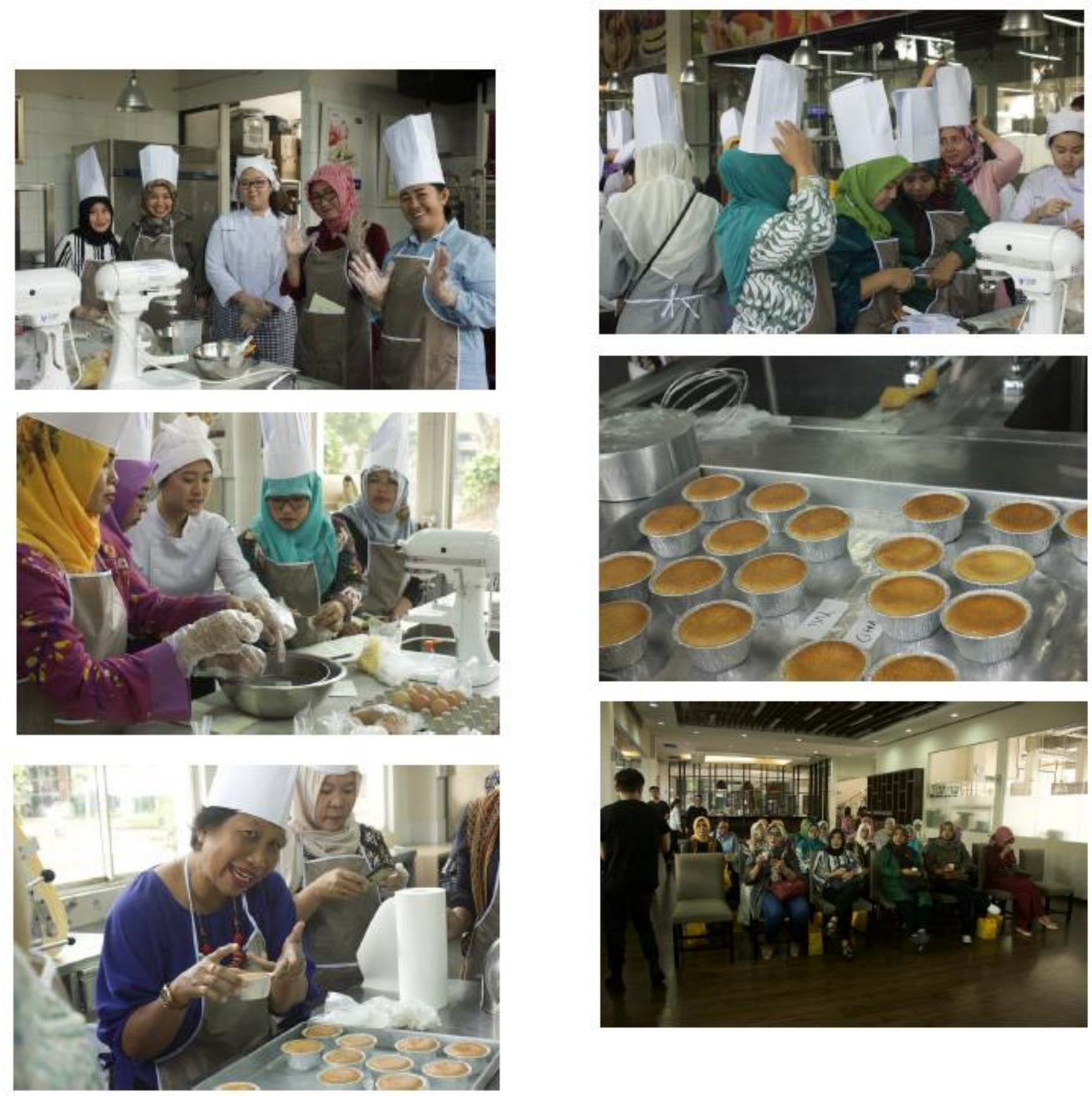

Ekonomi, Sosial, dan Budaya 

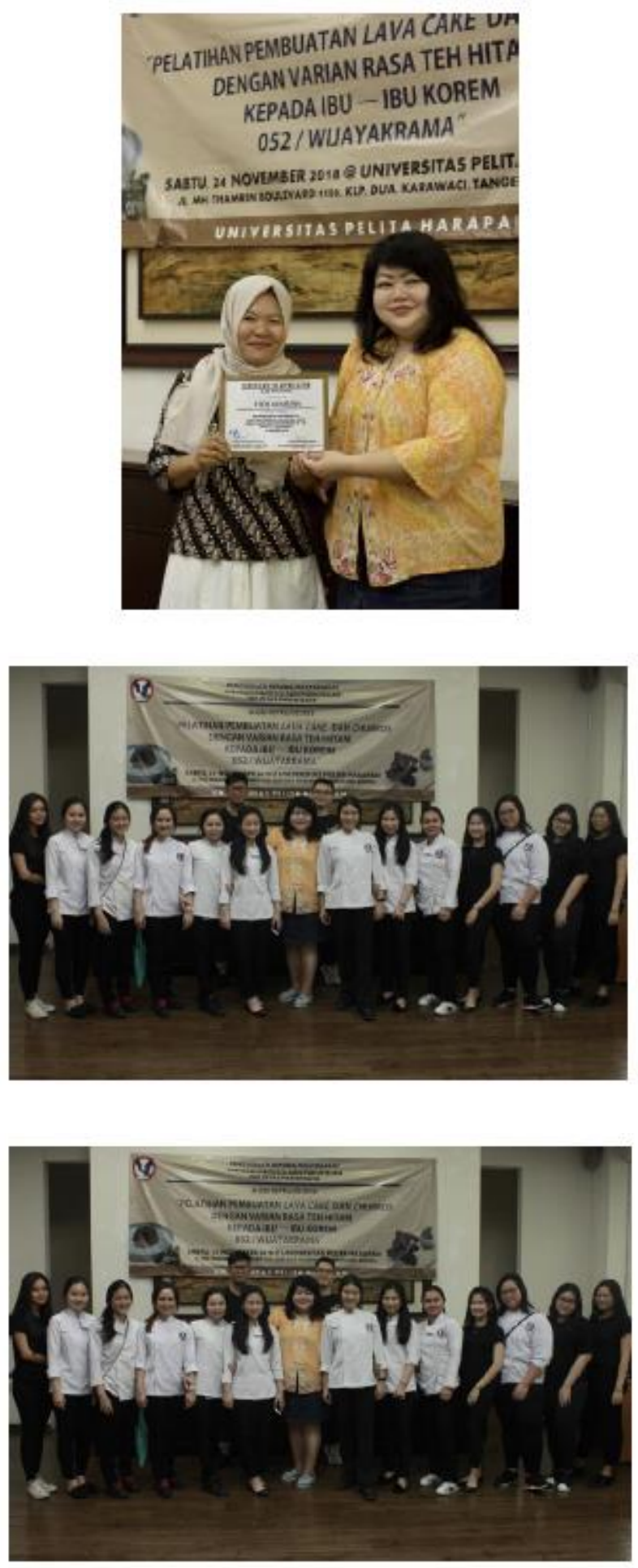

Ekonomi, Sosial, dan Budaya 


\section{REFERENSI}

Chrystal, Paul. (2014) Tea: A Very British Beverage. United Kingdom: Amberly Publishing.

Heiss, Mary Lou. (2010). The Story of Tea: A Cultural History and Drinking Guide. New York: Ten Speed Press.

Krondl, Michael (2011). Sweet Invention: A History of Dessert. USA: Chicago Review Press.

Moentamaria, Againa, Ridhawati, Chumaidi, \& Hendrawati. (2016). Hidrolisis Minyak Kelapa Dengan Lipase Terimobilisasi Zeolit Pada Pembuatan Perisa Alami, h85. Diakses dari:

https://www.neliti.com/publications/74748/hidr olisis-minyak-kelapa-dengan-lipaseterimobilisasi-zeolit-pada-pembuatan-peri
Moffat, Muriel (2013). Afternoon Tea: A Timeless Tradition.Vancouver: D\&M Publisher, Inc.

Ratna Somantri (2012). Iced Tea Book. TransMedia Pustaka. Indonesia: CiganjurJagakarta, Jakarta Selatan.

Ratnani (2009). Kecepatan Penyerapan Zat Organik Pada Limbah Cair Industri Tahu Dengan Lumpur Aktif, h1. Diakses dari https://core.ac.uk/display/85051934.

Yulianto, Arifan, Ariwibowo, Hartati, \& Mustikaningtyas. (2007). Pengembangan Proses Inaktivasi Enzim Polifenol Oksidase untuk Produksi Teh Hijau Berkatekin Tinggi, h24. Diakses dari https://www.neliti.com/id/publications/230590/ pengembangan-proses-inaktivasi-enzimpolifenol-oksidase-untuk-produksi-teh-hijau 